Research Article

\title{
Optimization of Culture Conditions for Growth of Marine Phytoplankton
}

\author{
Kunguma Kannika Maharajan ${ }^{1}$, Panneerselvam Karthikeyan ${ }^{2}$, Shambanagouda Rudragouda \\ Marigoudar ${ }^{2 *}$, Krishna Venkatarama Sharma ${ }^{2}$, Kasthuri Revathi ${ }^{3}$ \\ ${ }^{1}$ PG and Research Department of Zoology, Ethiraj College for Women (Autonomous), Affiliated to University \\ of Madras, Ethiraj Salai, Egmore, Chennai 600008, India \\ ${ }^{2}$ National Centre for Coastal Research, Ministry of Earth Sciences, NIOT Campus, Chennai 600100, India \\ ${ }^{3}$ Meenakshi Academy of Higher Education, Chennai 600078, India
}

Article history:

Submission April 2019

Revised August 2019

Accepted November 2019

*Corresponding author:

E-mail:

srmarigoudar@nccr.gov.in

\begin{abstract}
The present study investigated the optimum levels of ambient temperature, salinity and light intensity for the growth of marine diatoms and microalgae. The growth of marine diatoms Thalassiosira subtilis, Entomoneis paludosa and microalgae Isochrysis galbana were optimized. Phytoplankton subcultures were prepared in filtered natural seawater enriched with $\mathrm{f} / 2$ media for diatoms and Conway media for I. galbana. Cultures were grown under three different levels of parameters such as temperature, salinity and light intensity consisting of 27 combinations in 96well plates. Ten replicates of cultures were maintained for each combination of ambient levels. The algal density was determined by spectrometric absorbance of culture at $680 \mathrm{~nm}$. Likewise, the growth was estimated from the rate of increase in the absorbance values over a period of time. The duration of growth differed between the species. The I. galbana was grown for prolonged culture duration of 15 days followed by E. paludosa with 12 days and T. subtilis with 8 days. Ambient temperature and light intensity are the driving parameters for optimum growth of the species studied while the optimum salinity of 30 psu was observed for all species. Ambient levels of $28^{\circ} \mathrm{C}, 30$ psu and 2500 lux were found optimum for the growth of $T$. subtilis and E. paludosa attained its optimum growth at $24^{\circ} \mathrm{C}, 30$ psu and 2500 lux. Higher light intensity (4500 lux) at $24^{\circ} \mathrm{C}$ and 30 psu has enhanced the growth of I. galbana.
\end{abstract}

Keywords: Diatom, Growth Optimum levels, Temperature, Salinity, Light

\section{Introduction}

Phytoplankton is being explored for their potential in many fields concerned with ecological and industrial aspects. Therefore, constant efforts are being made since last century towards the micro algal culturing techniques [1]. Microalgae were cultured for aquaculture during beginning of the last century [2]. Many recent studies have reported the advantages of plankton culture under controlled conditions for attaining greater quality and quantity of biomass at lesser duration. Phytoplankton are potentially important for environmental impact assessment studies, synthesis of bioactive compounds, pigments, biofuels and applications in phytoremediation of contaminated wa- ter [3-8]. Most of the phytoplankton are sensitive to the ambient environmental conditions hence their community structure and biodiversity depends on ambient levels of nutrients, temperature, salinity, $\mathrm{pH}$ and light [9]. There are more than 5000 marine phytoplankton species identified of which less than $10 \%$ of the species can be cultured under laboratory conditions and only a few of them on a mass scale [10]. The cultivation of plankton depends on the identification of optimum conditions for specific groups/species. The levels of nutrients and minerals were reported for most of the marine microalgae and diatoms as culture media recipes $[11,12]$. These media recipes are described with different level of macronutrients 
(C, N, P, S, K, Na, Fe, Mg, and $\mathrm{Ca}$ ) and micronutrients (B, Cu, Mn, Zn, Mo, Co, V, and Se). Most of these media are suitable for culturing a group of plankton like $\mathrm{f} / 2$ media for diatoms, Conway and B11 media for green microalgae [13]. Unlike media composition, the optimum ambient environmental parameters such as temperature, salinity, light intensity and photoperiod differs among the species [14]. Therefore, optimizing environmental factors for linear growth rate is essential for the conduct of bioassays to derive toxicity values towards environmental impact assessments. Temperature, salinity and light intensities control the rates of all chemical reactions related to algal growth, metabolism and biochemical profile of microalgae [15, 16, 17].

Few microalgal species have been extensively studied for attaining better quantity and quality in biomass and biochemical composition by altering of culture conditions $[18,19]$. However, reports on optimum conditions for the crucial parameters like growth, biomass and biochemical profile are scarce for most of common diatoms and occasional phytoplankton. Diatoms Thalassiosira subtilis [20] and haptophyte microalga Isochrysis galbana [21] have wide distribution and are extensively studied for their various applications such as nutrition, biofuels and environmental impact assessment. The benthic diatom Entomoneis paludosa [22] is a rare cultured species and is largely unexplored for growth characteristics and biochemical profiles. Hence the present study was conducted for the identification of optimum culture conditions of temperature, salinity and light intensity for the growth of diatoms and microalgae.

\section{Material and Methods \\ Diatom and microalgae culture}

Phytoplankton samples were collected from the coastal waters of Ennore (Lat. 13.232190; Long. 80.330068) by horizontal towing of plankton net ( $20 \mu$ mesh size). The samples were transferred into polypropylene bottles and transported to laboratory. The diatoms T. subtilis and E. paludosa were identified using the morphological identification characteristics [23]. The diatoms were isolated by filtration and serial dilution methods. The haptophyte microalgae I. galbana was obtained from micro algae culture laboratory, NIOT, Chennai, Tamil Nadu. The mono-species cultures were maintained under controlled laboratory conditions in filtered sterilized seawater enriched with f/2 media [24] and Conway media [25] for diatoms and microalgae respectively.

\section{Experimental design}

Growth of two species of marine diatoms and I. galbana were examined with 27 combinations of temperature, salinity and light intensity experiments. The 27 probable combinations were made from three different levels of temperature (24, 28 and $30^{\circ} \mathrm{C}$ ), salinity $(28,30$, and $33 \mathrm{psu})$ and light intensity $(1500,2500$, and 4500 lux which are equivalent to 20, 35 and $60 \mu \mathrm{mol}$ photon $\mathrm{m}^{-2} \mathrm{~s}^{-1} \mathrm{re}-$ spectively). Separate subcultures for each species were made in $100 \mathrm{ml}$ of media with three different salinities. Culture media in different salinities without plankton cells were used as blank. Totally nine 96 well plates (Nunc, Denmark) with cultures and blanks were used for the experiment. Every plate was loaded with $250 \mu \mathrm{l}$ of culture of each species in different salinities and blanks. 90 wells were loaded in each plate consisting of ten replicated cultures (30 wells/species $\times 3$ salinity $=90$ wells) and remaining 6 wells for media blanks in duplicate. The plates were separated into 3 sets and each set of plates were placed at different light intensities in three different temperature-controlled rooms. The different light intensities were obtained by placing the plates at different distances from the light source of white fluorescent lamps. Photoperiod was maintained at $12 \mathrm{~h}$ light and $12 \mathrm{~h}$ dark cycle. The plates were measured for the growth of alga/diatoms at $24 \mathrm{~h}$ interval.

\section{Measurement of physico-chemical parameters}

Environmental parameters such as temperature, salinity and light intensity were maintained during the growth experiment. The temperature in the experimental chamber was measured twice a day using a glass mercury thermometer with $0.1^{\circ} \mathrm{C}$ resolution. Salinity was measured during the preparation of the test media using refractometer (Make: ATAGO, Serial No. 0144294). The light intensity was measured by placing photoreceptor cell of a digital lux meter (Make: Lutron, Model: LX-101) on the culture plates.

\section{Growth estimation}

The absorbance of culture at $24 \mathrm{~h}$ interval was used for the estimation of growth [26]. The blanks 
and cultures in the wells were mixed thoroughly using micropipette for homogenization. Absorbance was measured at $680 \mathrm{~nm}$ using multi-mode microplate reader (BioTek Instruments, Synergy H1). The absorbance of blank was subtracted and absorbance data of cultures was acquired from Gen5 ${ }^{\mathrm{TM}}$ software.

\section{Statistical analysis}

Analysis of variance (ANOVA) with multivariance analysis was performed for each species to differentiate the cultures on the basis of growth patterns between the various combinations of environmental parameters employed.

\section{Results and Discussion}

Growth characteristics of T. subtilis, E. paludosa, and I. galbana under different levels of temperature, salinity and light intensity were studied for their entire culture period from lag phase to decline phase. The absorbance of culture was measured at $24 \mathrm{~h}$ intervals at $680 \mathrm{~nm}$ in multi-mode microplate reader. The initial absorbance of cultures was recorded in the range of $0.077-0.080$ for $T$. subtilis, 0.066-0.069 for E. paludosa and 0.0900.100 for I. galbana. Subsequently, the cultures reached their maximum absorbance values at different durations among the combinations and the species. The growth curves are plotted using the absorbance values of culture over a period of time for each species and combinations (Figure 1 and 2). Then the growth curves were statistically compared by using ANOVA with multi-variance analysis (Figure 3). Significant changes in the growth curves were observed under different levels in ambient parameters. Few combinations yielded higher growth with maximum absorbance value during the experiment $(0.13,0.21$ and 0.35 in cultures of T. subtilis, E. paludosa, and I. galbana respectively). All the three parameters influenced differently on the growth of diatoms and microalgae. Five most optimum level combinations of parameters were picked out based on the statistical analysis of the growth under all the combinations examined (Figure 4). The optimum levels were in the order of MTMSHL, MTHSHL, HTHSHL, LTMSHL and HTMSHL for the growth of T. subtilis; LTMSML, HTLSHL, HTMSHL, HTHSHL and HTLSML for the growth of E. paludosa; LTMSHL, MTLSHL, MTHSHL, MTHSML and MTMSHL for the growth of I. galbana (Figure 4)
Table 1. Ranges of temperature, salinity and light intensity and details of acronyms

\begin{tabular}{cccc}
\hline & Low & Medium & High \\
\hline Temperature & 24 & 28 & 30 \\
$\left({ }^{\circ} \mathrm{C}\right)$ & $(\mathrm{LT})$ & $(\mathrm{MT})$ & $(\mathrm{HT})$ \\
Salinity & 28 & 30 & 33 \\
(psu) & $(\mathrm{LS})$ & $(\mathrm{MS})$ & $(\mathrm{HS})$ \\
Light Intensity & 1500 & 2500 & 4500 \\
(lux) & $(\mathrm{LL})$ & $(\mathrm{ML})$ & $(\mathrm{HL})$ \\
\hline
\end{tabular}

and (Table 1).

Salinity and light intensity were the major influencing factors for the growth of $T$. subtilis. The reduction in the growth of $T$. subtilis was observed at $24^{\circ} \mathrm{C}$ to $28^{\circ} \mathrm{C}$ combined with lower salinity of 28 psu. Growth of E. paludosa depends on temperature and light intensities at higher levels. The temperature of $30^{\circ} \mathrm{C}$, light intensities of 35 and 60 $\mu \mathrm{mol}$ photon $\mathrm{m}^{-2} \mathrm{~s}^{-1}$ along with the salinity ranges of 28, 30 and 33 psu were found to be the optimum levels for the growth of E. paludosa. All the combinations with higher temperature inhibited the growth of I. galbana. Maximum growth inhibition of diatom T. subtilis was observed at lesser temperature and higher salinities. Contrastingly, maximum growth inhibition in E. paludosa was found at higher temperature level and lower light intensity. Lower temperature and salinity were responsible for the growth reduction in I. galbana cultures.

Culture optimization of phytoplankton is important to explore their potential applications. The ambient levels of temperature, salinity and light intensity were studied for their impact on the growth of T. subtilis, E. paludosa, and I. galbana. Apparent optimum levels of these parameters were revealed by growth characteristics under different combinations (Figure 1 and 2). The significant differences in growth pattern of each species indicated the combined effect of temperature, salinity and light intensity at different levels (Figure $3)$. Among the three selected parameters, temperature and light intensity were found to be more significant parameters than salinity. Growth of diatoms and I. galbana demonstrated that light and temperature are influencing the culture in combination. Higher light intensities combined with lesser salinities promoted the growth. Diatoms exhibited their tolerance to higher levels of temperature, salinity and light intensity. The haptophyte microalga, I. galbana is sensitive to higher tempe- 


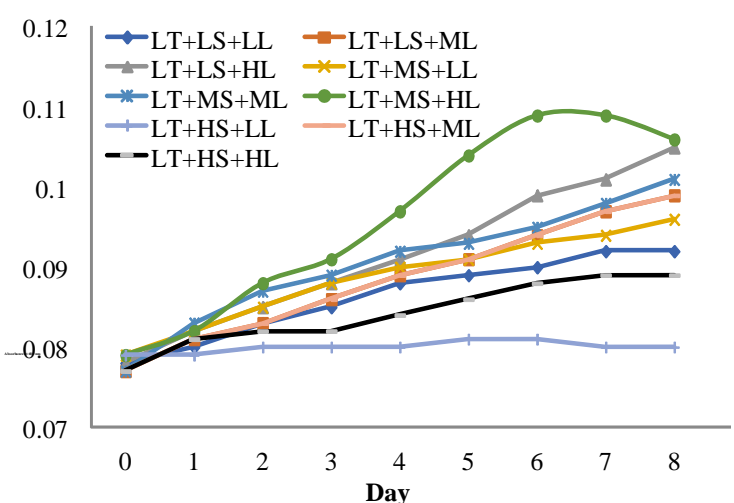

(a)

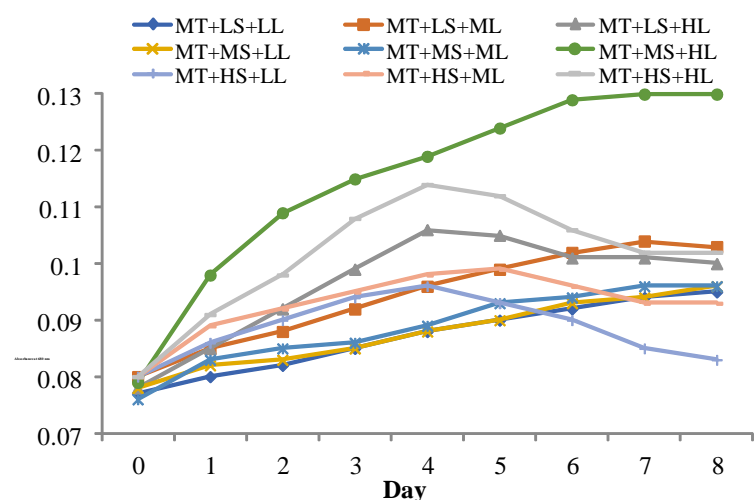

(b)

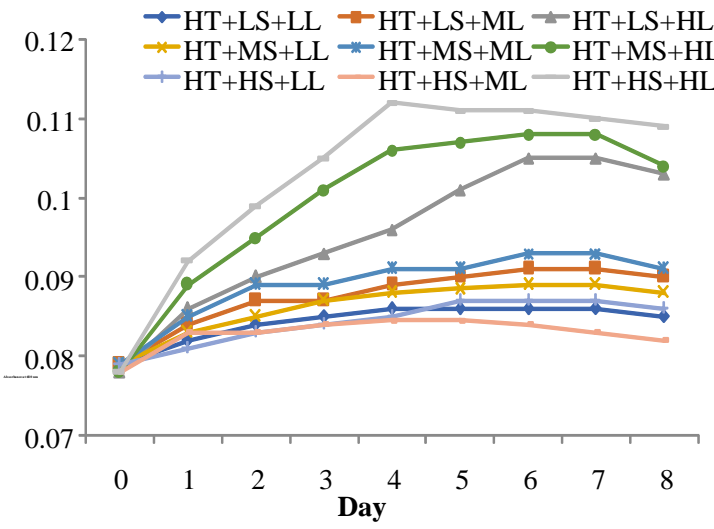

(c)

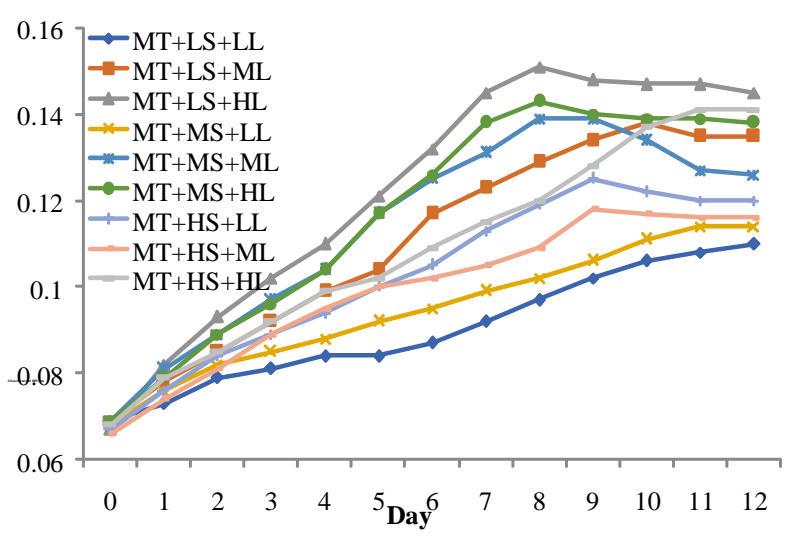

(e)

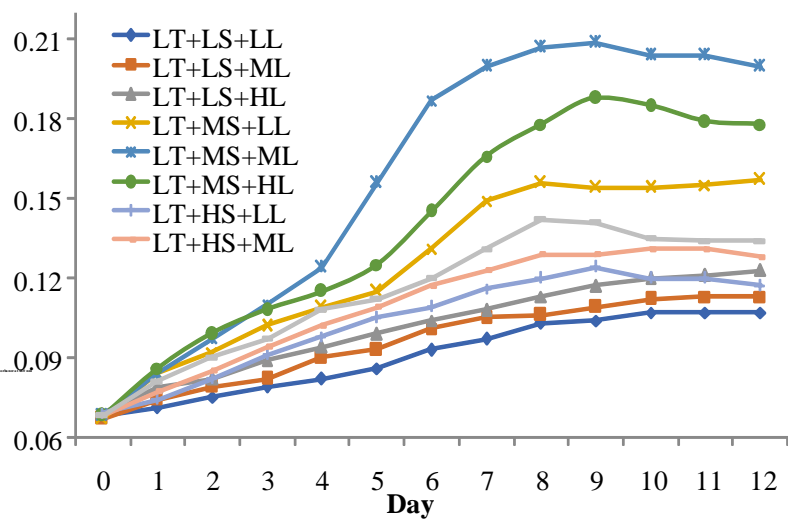

(d)

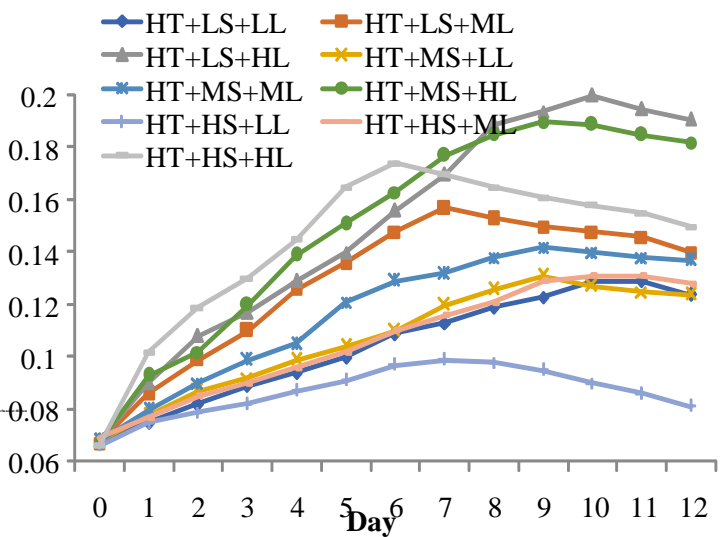

(f)

Figure 1. Growth curves of diatoms under different levels of temperature, salinity and light intensity in different combinations. Growth of $T$. subtilis at varying salinity and light intensities with $24^{\circ} \mathrm{C}, 28^{\circ} \mathrm{C}$ and $30^{\circ} \mathrm{C}$ of temperatures respectively (a, b, and c); Growth of E. paludosa at varying salinity and light intensities with $24^{\circ} \mathrm{C}, 28^{\circ} \mathrm{C}$ and $30^{\circ} \mathrm{C}$ of temperatures respectively (d, e, and f) 


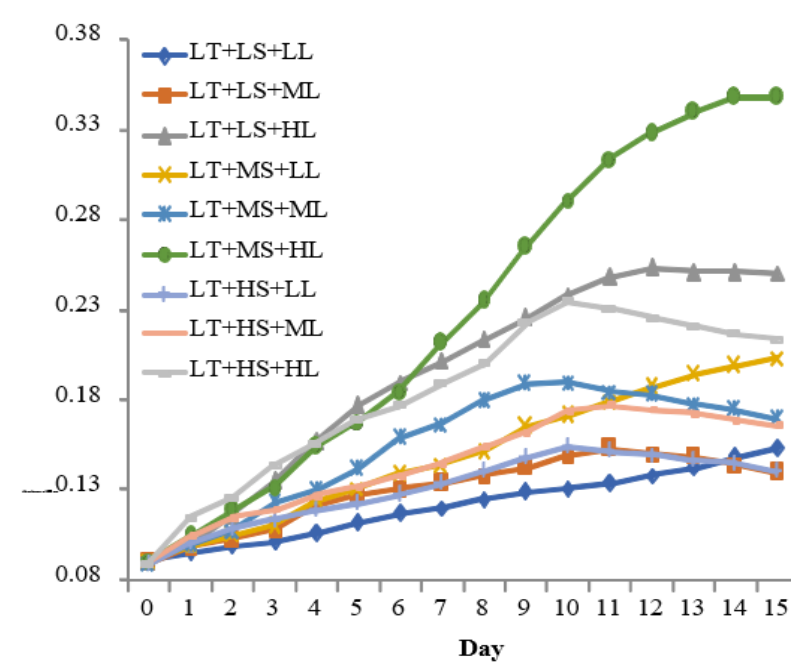

(a)

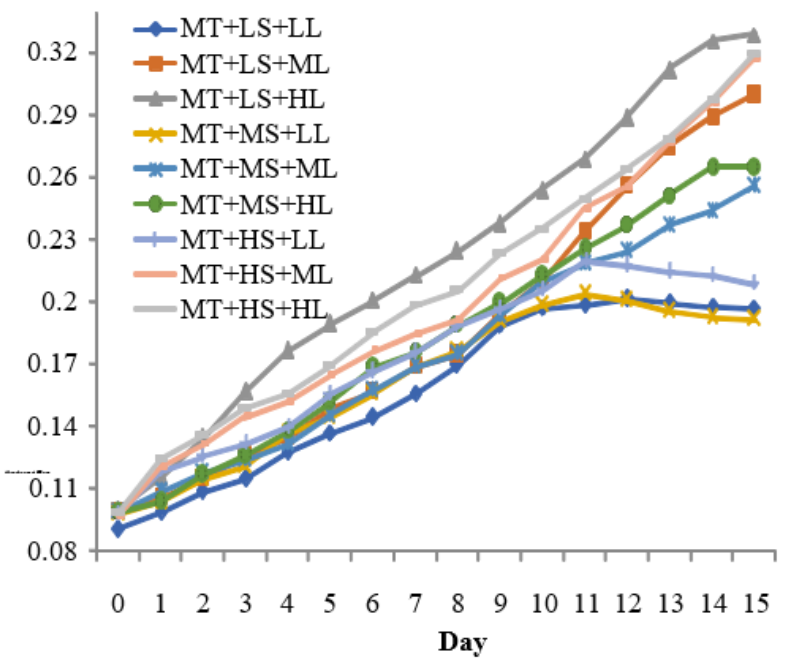

(b)

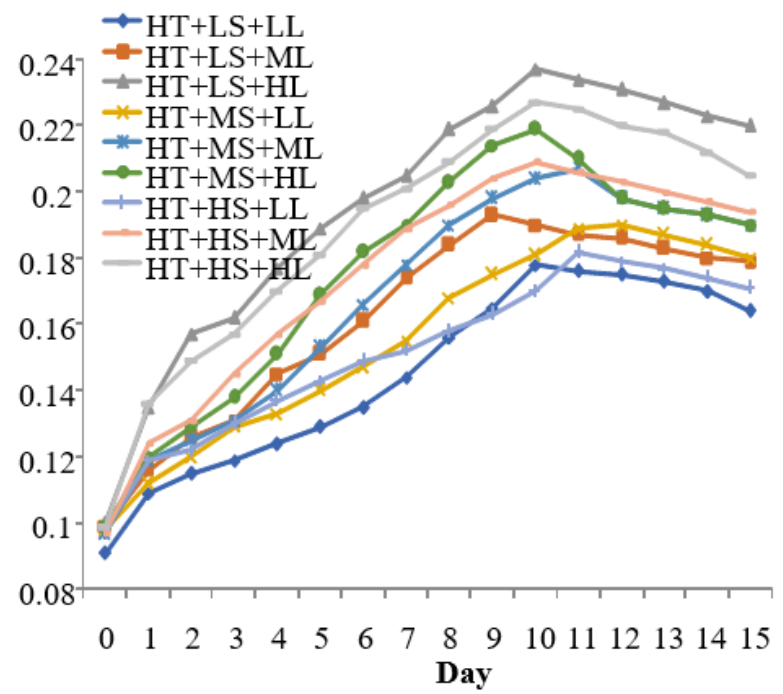

(c)

Figure 2. Growth of I. galbana at $24^{\circ} \mathrm{C}$ (a), $28^{\circ} \mathrm{C}$ (b), and $30^{\circ} \mathrm{C}$ (c) of temperatures respectively with varying salinity and light intensities.

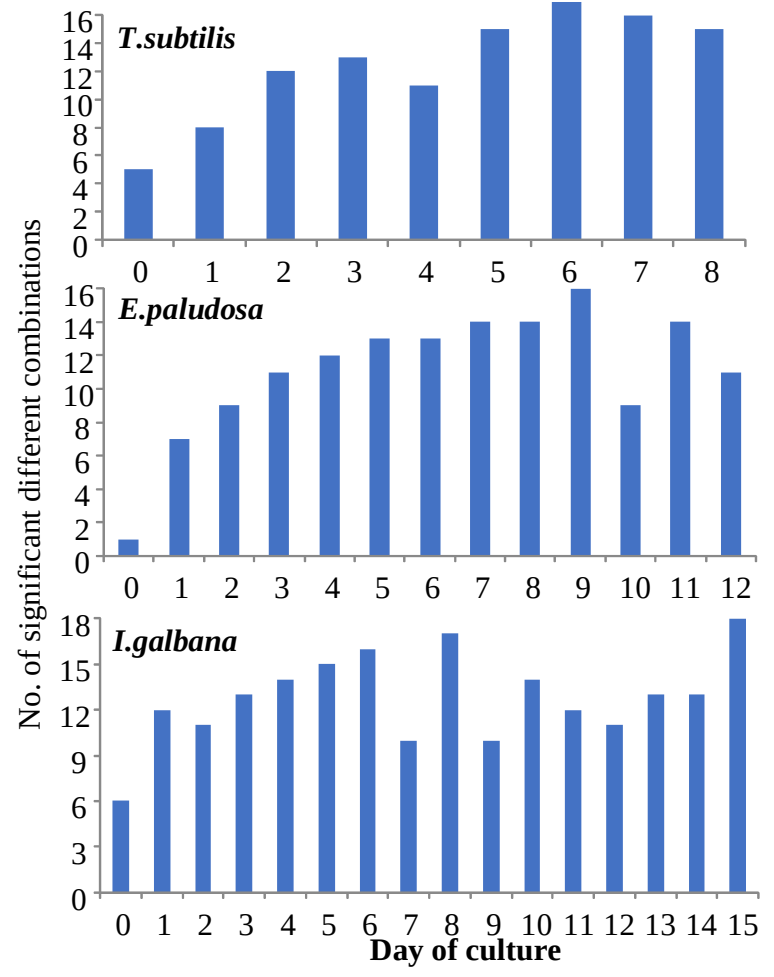

Figure 3. Significant difference under different levels of environmental parameters among the combinations

rature $\left(30^{\circ} \mathrm{C}\right)$ and requires higher light intensity (60 $\mu \mathrm{mol}$ photon $\mathrm{m}^{-2} . \mathrm{s}^{-1}$ ) for optimum growth. The reduced exponential phases in diatom cultures were observed for the combination of temperature, salinity and light intensity at higher levels. The diatoms $T$. subtilis and E. paludosa attained their maximum growth on fourth and sixth day and thereafter it declined at higher levels of temperature, salinity, and light.

The temperature dependence of the growth rate can differ considerably among species [27]. The optimum temperature range was found to be 24 to $30^{\circ} \mathrm{C}$ for the growth of diatoms $T$. subtilis and E. paludosa. Similarly, an optimum temperature of 24 to $28^{\circ} \mathrm{C}$ was identified for I. galbana. It is important to discuss the temperature dependency that has been reported previously in comparison to the present results. An optimum temperature of $25-30^{\circ} \mathrm{C}$ has been reported as an ideal range for the growth of diatom Chaetoceros sp. [28] and $20-25^{\circ} \mathrm{C}$ was suitable for the growth of C. pyrenoidosa [29]. Equally, $30^{\circ} \mathrm{C}$ was found as optimum for higher growth of Chlorella minutissima [30] and for maximum biomass and lipid production by Chlorella pyrenoidosa [31]. Diatoms 


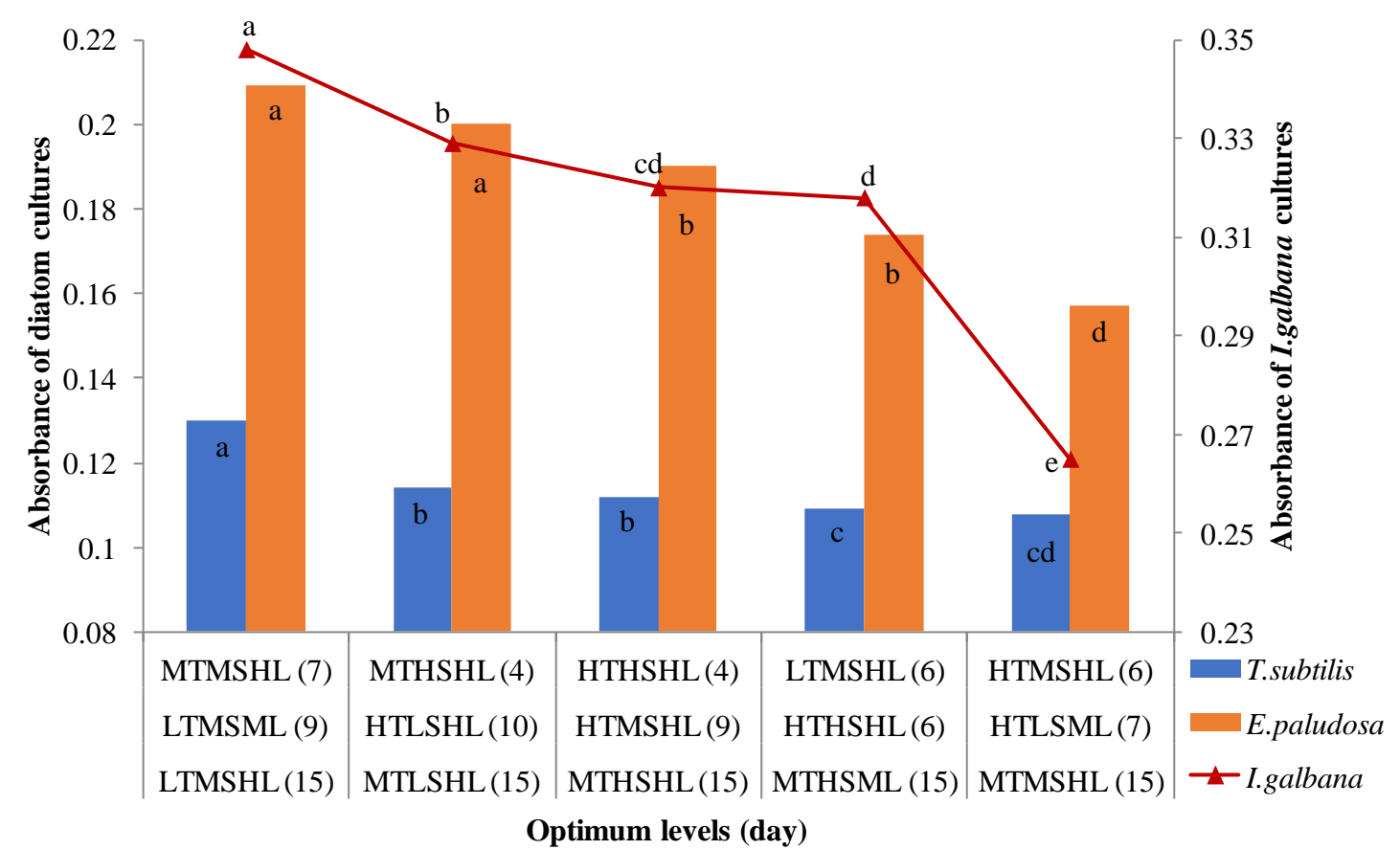

Figure 4. Optimum levels of environmental parameters for the growth of diatoms and I. galbana (Each data points with different alphabets are significantly different $(\mathrm{p} \leq 0.05)$ among the optimum levels and combinations).

Chaetoceros calcitrans and Skeletonema costatum also exhibited high growth at $30^{\circ} \mathrm{C}$, above which the algal culture crash was observed [32]. Likewise, growth inhibition and depletion of biomass production in Chlorella sorokiniana was recorded at elevated dissolved oxygen and temperature [33]. The optimum level of temperature is related to their habitat ranges. The rise in temperature above the species optimum level could result in low growth rate of phytoplankton [34]. Creswell [35] stated that the tropical and sub-tropical phytoplankton species grow best at temperatures ranging from 16 to $27^{\circ} \mathrm{C}$. Therefore, it is pertinent to note that, the diatoms are sustained in a wide range of temperature and microalgae prefer to grow at slightly lower temperature than the diatoms. However, the influence of physiological and water quality parameters cannot be overlooked.

In the present study, salinity of 28-30 psu was found to be optimum for the growth of $T$. subtilis, E. paludosa, and I. galbana. The higher salinity of 33 psu affected the growth of diatoms and microalgae. Lower salinity led to maximum growth, cell density, biomass and chlorophyll content of Chaetoceros calcitrans [18, 36]. Increasing salinity from 40 to 60 psu decreases the growth of marine Chlorella saccharophila [37]. Similarly, salinity of 15 to 25 psu is reported to be optimum for the maximum growth of diatom Skletonema costum and Chaetoceros sp. [38]. In contrast, the diatom species such as Thalassionema eccentrica and Pseudo-nitzschia seriata were able to survive at hypersaline conditions up to 150 psu [39]. Therefore, respiration, photosynthesis and growth are affected at hypersaline conditions above the optimum levels due to the overloading of the osmoregulatory mechanism [40, 41]. Similarly, salinity at higher levels demonstrated the reduced chlorophyll resulting to limitation in assimilation rate [42].

Light is required for photochemical production of Adenosine triphosphate (ATP) and Nicotinamide adenine dinucleotide phosphate-oxidase (NADPH). Equally, the light and dark photoperiod is essential for the synthesis of biochemical molecules [43]. Hence, the intensity of light and its duration is the major influencing factor for the growth of phytoplankton. The results exhibited that the growth of diatoms and I. galbana is optimum in the light intensity of 35 to $60 \mu \mathrm{mol}$ photon $\mathrm{m}^{-2} \cdot \mathrm{s}^{-1}$. Light intensity of $60 \mu \mathrm{mol}$ photon $\mathrm{m}^{-2} \cdot \mathrm{s}^{-1}$ is optimum for the growth of diatom T. subtilis and microalga I. galbana. Lesser light intensity may provide insufficient photon energy for the photo- 
synthesis; hence some phytoplankton demonstrated their adaptation by increasing the size of photo-harvesting apparatus chloroplast [44, 45]. On the other hand, higher light intensities can harm the algae by damaging the photosynthetic pigments and photo-oxidation of biomolecules $[46,47]$. Thus, the amount of light and duration of photoperiod is unequal among the phytoplankton species [48].

\section{Conclusion}

The study of growth characteristics of microalgae and diatoms are essential for various applications. Prolonged exponential growth phase with linear growth rate is necessary for the utilization of particular species for bioassay experiments. Perhaps, fastest growth is desirable for employing the microalgae for remediation studies. Similarly, attaining the highest quality of biochemical profile in algal biomass is the objective for utilization of algae to nutrition and bio-fuel production. In this study, five optimum conditions were identified for linear growth rate, and highest biomass production in lesser durations for diatoms and haptophyte microalgae I. galbana. Further studies on biochemical profiles and mass scale production are suggested for better utilization of these species to a maximum extent.

\section{Acknowledgment}

The authors are thankful to the Ministry of Earth Sciences, Government of India for implementing the project on 'Marine Ecotoxicology and Ecological Risk Assessment'. The authors are grateful to Dr. M. V. Ramana Murthy, Director, National Centre for Coastal Research (NCCR) for support and encouragement to carry out the work.

\section{References}

1. Lee Y, Seen H (2004) Basic Culturing Techniques. In: Richmond A (eds) Handbook of Microalgal Culture: Biotechnology and Applied Phycology. Oxford, Blackwell Publishing Ltd. doi: 10.1111/j.1529-8817.2004.40502.x.

2. Preisig HR, Andersen RA (2005) Historical review of algal culturing techniques. Algal culturing techniques 65: 79-82.

3. Karthikeyan P, Manimaran K, Sampathkumar P, Rameshkumar L (2013) Growth and nutrient removal properties of the diatoms, Chaetoceros curvisetus and C. simplex under different nitrogen sources. Applied Water Science 3 (1): 49-55. doi: 10.1007/s13201-012-0056-z.
4. Shaker S, Nemati A, Montazeri-Najafabady N et al. (2015) Treating urban wastewater: Nutrient removal by using immobilized green algae in batch cultures. International Journal of phytoremediation 17 (12): 1177-1182.

5. Janssen C, Heijerick D (2003) Algal toxicity tests for environmental risk assessments of metals. In Reviews of environmental contamination and toxicology. Springer, New York, NY 23-52.

6. Dwivedi S, Srivastava S, Mishra S et al. (2010) Characterization of native microalgal strains for their chromium bioaccumulation potential: Phytoplankton response in polluted habitats. Journal of Hazardous Materials 173 (1-3): 95-101.

7. Heydarizadeh P, Poirier I, Loizeau D et al. (2013) Plastids of marine phytoplankton produce bioactive pigments and lipids. Marine drugs 11 (9): 3425-3471.

8. Shurin JB, Abbott RL, Deal MS et al. (2013) Industrial-strength ecology: trade-offs and opportunities in algal biofuel production. Ecology letters 16 (11): 1393-1404.

9. Singh SP, Singh P (2015) Effect of temperature and light on the growth of algae species : A review. Renewable and Sustainable Energy Reviews 50: 431-444. doi: 10.1016/j.rser.2015.05.024.

10. Lee YK (2001) Microalgal mass culture systems and methods: their limitation and potential. Journal of applied phycology 13 (4): 307-315.

11. Lin S (2005) ALGAL CULTURING TECHNIQUES. Journal of Phycology 41 (4): 906-908. doi: 10.1111/j.15298817.2005.00114.x.

12. Vonshak A (1993) Microalgae: laboratory growth techniques and the biotechnology of biomass production. In: Hall DO, Scurlock JMO, Bolhàr-Nordenkampf $\mathrm{H}$, et al. eds Photosynth. Prod. a Chang. Environ. Dordrecht, Springer Netherlands. pp 337-355.

13. Mata TM, Martins AA, Caetano NS (2010) Microalgae for biodiesel production and other applications: a review. Renewable and sustainable energy reviews 14 (1): 217-232.

14. Karthikeyan P, Manimaran K, Sampathkumar P, Rameshkumar L (2013) Growth and nutrient removal properties of the diatoms, Chaetoceros curvisetus and C. simplex under different nitrogen sources. Applied Water Science 3 (1): 49-55. doi: 10.1007/s13201-012-0056-z.

15. Guschina IA, Harwood JL (2009) Algal Lipids and Effect of the Environment on Their Biochemistry. In Lipids in Aquatic Ecosystems; Springer: Berlin, Germany 1-24.

16. Sandnes JM, Källqvist T, Wenner D, Gislerød HR (2005) Combined influence of light and temperature on growth rates of Nannochloropsis oceanica: linking cellular responses to large-scale biomass production. Journal of Applied Phycology 17 (6): 515525. doi: 10.1007/s10811-005-9002-x.

17. Tzovenis I, Pauw N De, Sorgeloos P (2003) Optimisation of TISO biomass production rich in essential fatty acids ll . Effect of different light regimes on the production of fatty acids. Aquaculture 216: 223-242. 
18. 1Kirrolia A, Bishnoi NR, Singh R (2014) Response surface methodology as a decision-making tool for optimization of culture conditions of green microalgae Chlorella spp. for biodiesel production. Annals of microbiology 64 (3): 1133-1147.

19. Silitonga AS, Masjuki HH, Ong HC et al. (2017) Optimization of extraction of lipid from Isochrysis galbana microalgae species for biodiesel synthesis. Energy Sources, Part A: Recovery, Utilization, and Environmental Effects 39 (11): 1167-1175.

20. Gran HH (1900) Bemerkungen über einige Planktondiatomeen. Nytt Magasin for Naturvidenskapene (38): 102-128.

21. Parke M (1949) Studies on Marine Flagellates. Journal of the Marine Biological Association of the United Kingdom 28 (1): 255-286. doi: 10.1017/S0025315400055302.

22. Patrick R, Reimer CW (1975) The diatoms of the United States exclusive of Alaska and Hawaii. Philadelphia Acad. Nat. Sci. Philadelphia. 2

23. Patrick R (1997) Identifying Marine Diatoms and Dinoflagellates. Carmelo R. Tomas. The Quarterly Review of Biology 72 (3): 345-345. doi: 10.1086/419914.

24. Guillard (1975) f/2 + Si (Guillard's medium for diatoms). 44 (1): 559001.

25. Walne P (1970) Studies on the food value of nineteen genera of algae to juvenile bivalves of the genera Ostrea, Crassostrea, Mercenaria, and Mytilis. Fish invest 26 (August): 1-62.

26. Dziosa K, Makowska M (2016) Monitoring of Chlorella sp. growth based on the optical density measurement. Problemy Eksploatacji 3: 197 - 206.

27. Jones RI, Reynolds CS (1985) The Ecology of Freshwater Phytoplankton. The Journal of Ecology 73 (2): 722. doi: $10.2307 / 2260522$

28. Raghavan G, Haridevi CK, Gopinathan CP (2008) Growth and proximate composition of the Chaetoceros calcitrans $f$. pumilus under different temperature, salinity and carbon dioxide levels. Aquaculture Research 39 (10): 1053-1058. doi: 10.1111/j.1365-2109.2008.01964.x.

29. Yang G, Luan Z, Zhou X, Mei Y (2010) The Researching of the Effect of Temperature on Chlorella Growth and Content of Dissolved Oxygen and Content of Chlorophyll. Mathematical and Physical Fisheries Science 8: 68-74.

30. Aleya L, Dauta A, Reynolds Colin S (2011) Endogenous regulation of the growth-rate responses of a spring-dwelling strain of the freshwater alga, Chlorella minutissima, to light and temperature European Journal of Protistology 47 (4): 239-244. doi: 10.1016/j.ejop.2011.05.003.

31. Han F, Wang W, Li Y et al. (2013) Changes of biomass, lipid content and fatty acids composition under a light-dark cyclic culture of Chlorella pyrenoidosa in response to different temperature. Bioresource Technology 132: 182-189. doi: 10.1016/j.biortech.2012.12.175.
32. Rai SV, Rajashekhar M (2014) Effect of pH, salinity and temperature on the growth of six species of marine phytoplankton. Journal of Algal Biomass Utilization 5 (4): 55-59.

33. Ugwu C, Aoyagi H, Uchiyama H (2007) Influence of irradiance, dissolved oxygen Concentration, and temperature on the growth of Chlorella sorokiniana. Photosynthetica 45 (2): 309-11.

34. Fogg GE, Brenda T (1966) Algal Cultures and Phytoplankton Ecology. The Journal of Applied Ecology 3 (1): 215. doi: $10.2307 / 2401679$

35. Creswell L (2010) Phytoplankton culture for aquaculture feed. Southern Regional Aquaculture Center (SRAC) Pub. No. 5004, Department of Agriculture, US.

36. Raghavan G, Haridevi CK, Gopinathan CP (2008) Growth and proximate composition of the Chaetoceros calcitrans $\mathrm{f}$. pumilus under different temperature, salinity and carbon dioxide levels. Aquaculture Research 39 (10): 1053-1058. doi: 10.1111/j.1365-2109.2008.01964.x.

37. Hirata H, Andarias I, Yamasaki S (1981) Effects of Salinity and Temperature on the Growth of the Marine Phytoplankton Chlorella saccharophila. Memoirs of Faculty of Fisheries Kagoshima University 30 257-262.

38. Lim LC (1991) An overview of live feeds production systems in Singapore. In: Rotifer Mircoalgae Cult. Syst. Proceeding a U.S. - Asia Workshop. pp 203-220.

39. Nagasathya A, Thajuddin N (2008) Diatom Diversity in Hypersaline Environment. Journal of Fisheries and Aquatic Science 3 (5): 328-333. doi: 10.3923/jfas.2008.328.333.

40. Vonshak A, Kancharaksa N, Bunnag B, Tanticharoen M (1996) Role of light and photosynthesis on the acclimation process of the cyanobacterium Spirulina platensis to salinity stress. Journal of Applied Phycology 8 (2): 119-124. doi: 10.1007/BF02186314.

41. Kirroliaa A, Bishnoia RN, Singh N (2011) Salinity as a factor affecting the physiological and biochemical traits of Scenedesmus quadricauda. Journal of Algal Biomass Utilization 2 (4): 28-34.

42. Rai A, Abraham G (1993) Salinity tolerance and growth analysis of the cyanobacterium Anabaena doliolum. Bulletin of Environmental Contamination and Toxicology 51 (5): 724-731. doi: 10.1007/BF00201651.

43. Cheirsilp B, Torpee S (2012) Enhanced growth and lipid production of microalgae under mixotrophic culture condition: Effect of light intensity, glucose concentration and fed-batch cultivation. Bioresource Technology 110: 510 - 516. doi: 10.1016/j.biortech.2012.01.125.

44. Danesi E, Rangel-Yagui C, Carvalho J, Sato S (2004) Effect of reducing the light intensity on the growth and production of chlorophyll by Spirulina platensis. Biomass Bioenergy 26: 329335. doi: 10.1016/S0961-9534(03)00127-2.

45. Bouterfas R, Belkoura M, Dauta A (2006) The effects of irradiance and photoperiod on the growth rate of three freshwater 
green algae isolated from a eutrophic lake. Limnetica 25647 656.

46. Janssen M, Kuijpers TC, Veldhoen B et al. (1999) Specific growth rate of Chlamydomonas reinhardtii and Chlorella sorokiniana under medium duration light/dark cycles: 13-87 s. Progress in Industrial Microbiology 35 (C): 323-333. doi: 10.1016/S0079-6352(99)80124-6.
47. Converti A, Casazza AA, Ortiz EY et al. (2009) Effect of temperature and nitrogen concentration on the growth and lipid content of Nannochloropsis oculata and Chlorella vulgaris for biodiesel production. Chem EngProcessProcess Intensification 48 1146-1151.

48. Richmond A (2004) Biological principles of mass cultivation. In: Richmond A ed Handb. Microalgal Mass. Oxford, Blackwell Publishing Company. p 566. 
This page is intentionally left blank. 